\title{
Request for Additional Pertinent Information Regarding 4 Extremity Stimulation Coverage from C2 Spinal Cord Stimulation Lead Placement
}

\section{TO THE EDITOR:}

The recent case series, "Neuromodulation of the Cervical Spinal Cord in the Treatment of Chronic Intractable Neck and Upper Extremity Pain: A Case Series and Review of the Literature," by Vallejo, Kramer, and Benyamin, (Pain Physician 2007; 10:305-311) furnishes us with valuable, insightful information regarding the ability to achieve moderate to excellent paresthesia coverage of all 4 extremities in certain patients.

In our practice, this has been a substantially helpful way in dealing with various diagnoses. This tool is predominately helpful in Complex Regional Pain Syndromes (CRPS), but has been an advantage in treating pain from multiple sclerosis, peripheral vascular disease, diabetes, and some comorbid conditions. We have found that 4-extremity coverage is achieved when the lead is placed with the rostral electrode tips in the $\mathrm{C} 2$ region with electrode strings over the physiologic midline (1).

Additionally, in our experience, this phenomenon appears to have some dependence upon the type of SCS architecture employed: we were unable to achieve 4-limb paresthesias in systems which utilize a singlecurrent source stimulation (voltage controlled) with a frequency limit of $120 \mathrm{~Hz}$. Utilizing a single-current source for stimulation which permitted frequencies up to $1500 \mathrm{~Hz}$, we saw a $15 \%$ incidence of stimulation in all 4 extremities. We have most commonly seen 4-extremity coverage ( $84 \%$ of patients with lead tip placement at $\mathrm{C2}$ ) using a system architecture which allows multiple independent constant current (MICC); this design allows the physician or SCS programmer the ability to control amplitude, pulse width, and frequency independently at each electrode simultaneously, not utilizing a program cycling mode (2).

We appreciate the technical problems with lead placements at these high cervical levels after anterior or anterior-posterior cervical fusion. Our solution has been to perform a small hemi-laminotomy at C3-4 to ease lead entry and positioning. Even after instrumentation of the cervical spine with anterior and posterior

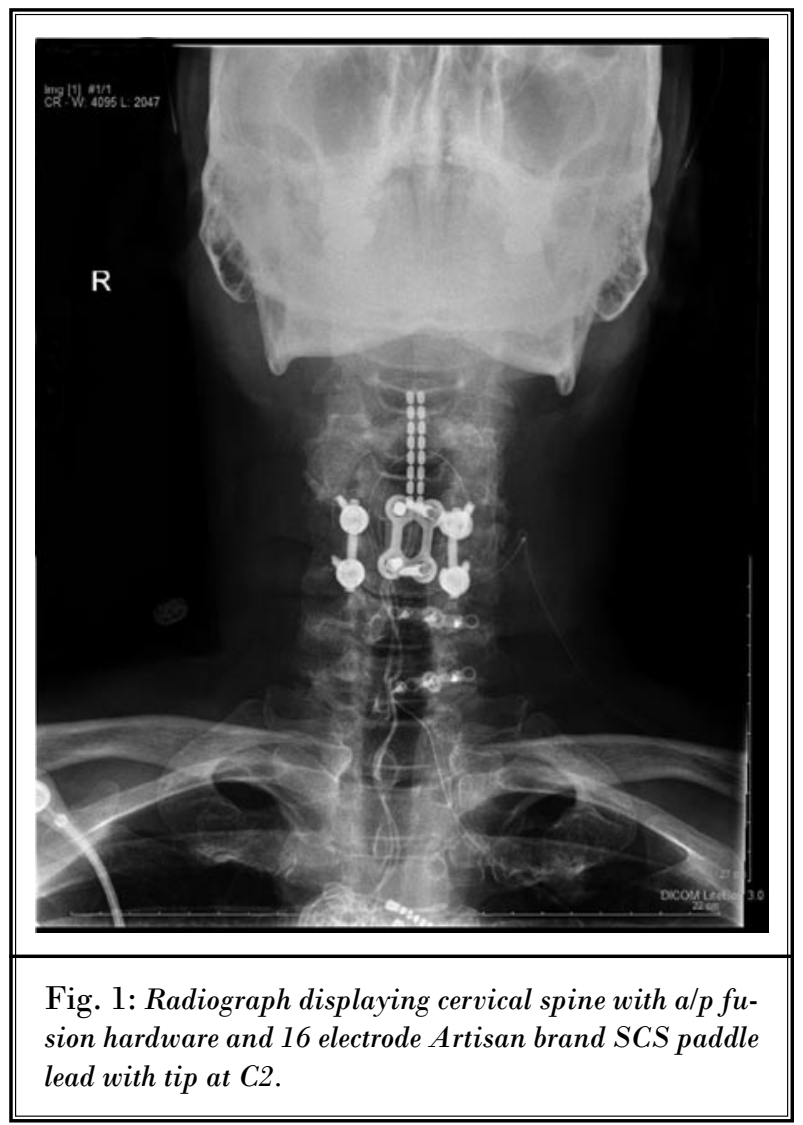

hardware, placement of a paddle lead is technically simple (Fig.1).

Our concern in Vallejo et al's case series is that 2 valuable pieces of clinical information were not included. The specific equipment utilized for each case would offer the reader important information as to whether the differences in technology were able to provide a greater chance of providing paresthesia and pain relief in this cohort. Secondly, an important, possibly critical piece of information is the mention of pulse width, frequency of stimulation (rate), and power settings used for each case. It is our opinion that since spinal cord stimulation is a functional surgical procedure, 
the settings utilized along with electrode position and polarity in relation to the neural targets is vital to determining the reason for success or failure (3).

As a clinical neurophysiologist responsible for intra- and post-operative programming, I would find it helpful to have such information. Publications which detail the specific technologies and programmed settings employed, and link these values to outcomes are an invaluable guide to the practicing clinicians. These data can even guide us in the pre-operative choice of equipment for implantation.

We thank the authors for their excellent case series and hope that this will inspire more clinicians to publish their unique experiences in our rapidly advancing practice of electrical neuromodulation.

\author{
James E. Hagen, MS \\ Director, Clinical Services and Research \\ Daniel S. Bennett, MD \\ Medical Director \\ Integrative Treatment Centers-Denver \\ 10835 N. Dover St, Suite 800 \\ Westminster, CO 80021 \\ jhagen@denverpain.com
}

\section{References}

1. Hagen JE, Bennett DS. Successful treat ment of 4-extremity complex regional pain syndrome type 1 with dual octapolar percutaneous leads and closely spaced electrodes. Poster Presentation, 7th Congress of the International Neuromodulation Society; Rome, Italy June 10-13, 2005.
2. Oakley J, Varga C, Krames E, Bradley K. 3 Real-time paresthesia steering using continuous electrical field adjustment. Part 1: intraoperative performance. Neuromodulation 2004; 7:157-167.
Gordon AT, Zou SP, Kim Y, Gharibo C. Challenges to setting spinal cord stimulator parameters during intraoperative testing: factors affecting coverage of low back and leg pain. Neuromodulation 2007; 10:133-141.

\section{Author Response to: Request for Additional Pertinent Information Regarding 4 Extremity Stimulation Coverage from C2 Spinal Cord Stimulation Lead Placement}

We would like to thank Hagen and Bennett for their enthusiastic comments about our paper titled, "Neuromodulation of the Cervical Spinal Cord in the Treatment of Chronic Intractable Neck and Upper Extremity Pain: A Case Series and Review of the Literature" (1). We agree with the authors that the placement of leads in the cervical region can be very beneficial to patients that suffer from painful conditions in widely separated regions of the body. Indeed, our case series highlights this point even to the extent of patients indicating coverage of occipital regions as well as all 4 extremities. We appreciate the reporting of similar clinical experiences from this group, as well as others (2). Hagen and Bennett state that approximately $84 \%$ of their patients report 4-extremity coverage with lead tip placement at C2 (3). In our case series, all 4 out of 4 patients (100\%) that implanted indicated the ability to obtain coverage in all 4 extremities. With a larger patient population to sample from this percentage may drop closer to the $84 \%$ reported by Hagen and Bennett (3). Interestingly, 2 out of the 4 patients also reported axial coverage. We feel that this is an important distinction and note that these 2 patients had devices implanted from 2 different companies, both of which were constant current type units. We reported that stimulators from 3 different manufacturers were utilized in the current case series. Given the low number of patients included in our case series, it is impossible to attribute "whether differences in technology were able to provide a greater chance of providing paresthesia and pain relief in this cohort" (3). However, we agree that stimulation parameters can be a valuable piece of information, so we have included the stimulation settings for all of those included in the case series that underwent device implantation (see Table 1). We absolutely agree that stimulation parameters as well as differences in lead and pulse generator technology may well play a role in the clinical efficacy of spinal neuromodulation. In particular, we were interested to read that high stimulation frequencies $(1500 \mathrm{~Hz})$ may increase the chance of generating paresthesias in 4 limbs. In our experience, longer pulse widths also seem to be associated with the ability to generate paresthesias map- 
Table 1. Stimulation parameters for multiple programs utilized in patients implanted with spinal cord stimulation systems.

\begin{tabular}{|c|c|c|c|}
\hline B & $\begin{array}{l}\text { Constant } \\
\text { Current }\end{array}$ & $\begin{array}{l}\text { P 1: } 50 \mathrm{~Hz} \\
\text { P 2: } 50 \mathrm{~Hz}\end{array}$ & $\begin{array}{l}\text { P 1: } 620 \mu \mathrm{s} \\
\text { P 2: } 470 \mu \mathrm{s}\end{array}$ \\
\hline$C$ & $\begin{array}{l}\text { Constant } \\
\text { Current }\end{array}$ & $\begin{array}{l}\text { P 1: } 60 \mathrm{~Hz} \\
\text { P 2: } 80 \mathrm{~Hz} \\
\text { P 3: } 38 \mathrm{~Hz} \\
\text { P 4: } 38 \mathrm{~Hz}\end{array}$ & $\begin{array}{l}\text { P 1: } 187 \mu \mathrm{s} \\
\text { P 2: } 150 \mu \mathrm{s} \\
\text { P 3: } 200 \mu \mathrm{s} \\
\text { P 4: } 200 \mu \mathrm{s}\end{array}$ \\
\hline D & $\begin{array}{l}\text { Constant } \\
\text { Current }\end{array}$ & $\begin{array}{l}\text { P 1: } 20 \mathrm{~Hz} \\
\text { P 2: } 60 \mathrm{~Hz} \\
\text { P 3: } 80 \mathrm{~Hz}\end{array}$ & $\begin{array}{l}\text { P 1: } 450 \mu \mathrm{s} \\
\text { P 2: } 425 \mu \mathrm{s} \\
\text { P 3: } 425 \mu \mathrm{s}\end{array}$ \\
\hline$E$ & $\begin{array}{l}\text { Constant } \\
\text { Current }\end{array}$ & $\begin{array}{l}\text { P 1: } 40 \mathrm{~Hz} \\
\text { P 2: } 40 \mathrm{~Hz}\end{array}$ & $\begin{array}{l}\text { P 1: } 580 \mu \mathrm{s} \\
\text { P 2: } 500 \mu \mathrm{s}\end{array}$ \\
\hline
\end{tabular}

ping from the occipital region down to the toes with high cervical lead placement. However, until quantitative sensory mapping studies as well as randomized, direct head-to-head trials are completed between devices, these types of clinical data will continue to remain anecdotal.
Ricardo Vallejo, MD, PhD

Jeffrey Kramer, PhD

Ramsin Benyamin, MD

Millennium Pain Center

1015 S. Mercer Ave.

Bloomington, Illinois, 61701

vallejo@millenniumpaincenter.com

\section{RefEREnCES}

1. Vallejo, R, Kramer, JM, Benyamin, R neuromodulation of the cervical spinal cord in the treatment of chronic intractable neck and upper extremity pain: a case series and review of the literature. Pain Physician 2007; 10:305-311.
2. Rauck, R., Wages, J, North, J. Four ex- 3 . tremity paresthesias with cervical spinal cord stimulation. Poster Presentation, 26th Annual Meeting of the American Pain Society; Washington, DC, May 2-5, 2007.
Hagen, JE, Bennett, DS Request for additional pertinent information regarding 4 extremity stimulation coverage from C2 spinal cord stimulation lead placement. Pain Physician 2007; 10:

\section{In ErRata:}

The address listed for Dr. Michael Whitworth in the letters to the editor section of the March Pain Physician journal was incorrect.

The correct address is

Michael L. Whitworth, MD

Advanced Pain Management Surgery

4010 Goeller Blvd Suite C

Columbus, IN 47201 